\title{
Role of LASER Stapedotomy in clinical improvement in subjectivetinnitus among patients with Otosclerosis- a retrospective analysis
}

\author{
Authors: Swati Suneha1* ,Kranti Bhavana2, Ragini Raina1, Meenu Kalyani3 \\ Authors Affiliations: (1) Senior Resident, (2) Additional Professor \& Head of Department, (3) Audiologist and \\ speech-language pathologist, \\ Department of Otorhinolaryngology-Head and Neck Surgery, All India Institute of Medical Sciences, Patna
}

\begin{abstract}
Objective: To determine the prevalence and severity of subjective tinnitus in patients undergoing LASER stapedotomy at the Department of Otorhinolaryngology, AIIMS Patna. To evaluate the efficacy of LASER stapedotomy in clinically significant improvement in tinnitus in these patients
\end{abstract}

Materials and methods: A retrospective study was conducted on 40 patients who underwent LASER stapedotomy from February 2018 to December 2019 at the Department of Otorhinolaryngology, AlIMS Patna. Pre- and post-operative audiological and tinnitus assessment was done. Hospital records were analyzed and otosclerotic patients with subjective tinnitus were included in the study. Prevalence and severity of tinnitus and accompanying degree of hearing loss across both genders were noted. Improvement in tinnitus postoperatively was evaluated. Results were analyzed using IBM SPSS Statistics software Version 20. Mean values were calculated and paired t-tests were applied to assess the role of LASER stapedotomy on tinnitus improvement.

Results: Out of a total of 40 stapedotomy patients, 29 (72.50\%) had tinnitus at presentation. The mean age of these patients was $29.59 \pm 9.3$ years. The mean gain in air conduction threshold (ACT) and air-bone gap (ABG) closure was $19.68 \mathrm{~dB}$ and $12.14 \mathrm{~dB}$ respectively. Unilateral tinnitus was seen in $55.17 \%$ and bilateral in $44.83 \%$ of patients. High-frequency hearing loss was found in $65.51 \%$ of patients. Postoperatively, $44.83 \%$ of patients experienced a complete resolution in tinnitus, while all of them had an improvement in tinnitus severity. This result was similar in both males and females.

Conclusion: Tinnitus is a frequent complaint of patients suffering from otosclerosis, which often takes a backseat in the treatment goals of a surgeon. It varies in severity and duration and is associated with a progressive worsening of hearing thresholds. LASER stapedotomy is an effective treatment modality, which not only improves post-operative hearing but also alleviates tinnitus to a great extent.

Study design: A retrospective observational study

Keywords: Otosclerosis. Tinnitus, LASER stapedotomy, Air Bone Gap (ABG)

\section{Introduction:}

Otosclerosis is a disorder of abnormal bone remodeling of the otic capsule and is one of the most common treatable causes of conductive hearing loss. Though primarily causing a conductive type of hearing loss due to stapes fixation, it often leads up to a mixed or sensorineural loss over time due to cochlear involvement in later stages.1,2

This disorder is most common in middle-aged population however, it can be often seen among children and older people as well.3-5 Familial history with a female preponderance is often associated with otosclerosis.6,7 The symptom spectrum of these patients involves varying degrees of hearing loss, tinnitus, and dizziness. Though hearing loss is frequently the major complaint, tinnitus is often associated with it and is distressing enough to cause a significant worsening in the quality of life in these patients.

Tinnitus can vary in its severity and duration among otosclerosis patients. It ranges from minimal to severe and can be chronic persistent or intermittent. Even if minimal or intermittent, it can be an annoying symptom to the patient and can cause sleep disturbance, anxiety and depression in its chronic form. 8

Since hearing loss is a quantifiable symptom, the focus of treatment modalities remains on the 
audiological gains of stapes surgery. Numerous studies have reported the hearing improvement achieved with different surgical methods i.e. partial or complete stapedectomy, cold stapedotomy and LASER stapedotomy. However, tinnitus is often the first symptom in otosclerosis, with $65-90 \%$ of patients reporting it in the course of the disease. 9

Data is sparse on the prevalence and severity of tinnitus in otosclerosis patients. This is often due to difficulty in its objective assessment. Also, the predictability of the postoperative status of tinnitus in patients is often extremely variable. 10 This results in an inadequate evaluation of pre- and postoperative tinnitus status in stapedotomy patients, causing a substantial knowledge gap regarding this widely prevalent phenomenon. To the best of our knowledge, a study evaluating the role of LASER stapedotomy in the improvement of subjective tinnitus in otosclerotic patients has not yet been done on the Indian population. Hence we conducted this study to analyze our results in these patients.

\section{Materials and methods:}

Study design: It was a retrospective study of 40 otosclerotic patients undergoing LASER stapedotomy at the Department of Otolaryngology, AlIMS Patna from February 2018 to December 2019. Patients who were diagnosed with otosclerosis based on clinical examination, audiological tests and high-resolution CT scan of temporal bone were evaluated. Data of those patients who had concomitant tinnitus was analyzed in the study. All patients underwent stapedotomy after a well informed written consent for the procedure. $\mathrm{CO} 2$ LASER was used to create a stapedotomy hole with either Teflon or Titanium prosthesis insertion under general anaesthesia. Structured interviews and psychoacoustic measurement techniques were employed to assess tinnitus presence and severity both pre- and postoperatively. Hearing improvement in terms of Air Conduction Threshold (ACT) gain at frequencies of $0.25,0.5,1,2,4$ and 8 $\mathrm{kHz}$ and Air Bone Gap (ABG) closure was measured preoperatively and at 1-month post-operative interval.

\section{Inclusion criteria-}

a) Patients with a clinical and audiological diagnosis of otosclerosis b) Patients with the presence of coexisting tinnitus

c) Patients who gave written consent for the procedure

d) Patients who underwent LASER stapedotomy

\section{Exclusion criteria-}

a) Patients who had no tinnitus at presentation

b) Patients not giving consent for the surgery

c) Patients operated via a non-LASER technique

Sample size - A total of 29 out of 40 LASER stapedotomy patients fulfilled the above criteria and were thus included in the data analysis.

Statistical analysis: Data was entered on Microsoft Excel Sheet version 2007. Statistical analysis was done by IBM SPSS Statistics software Version 20. Descriptive analysis was done and means were calculated. Paired t-tests were applied. Results were interpreted using analysis tables and bar graphs.

\section{Results:}

We evaluated 40 patients undergoing LASER stapedotomy at our center. Of these, 29 (72.50\%) patients had clinically significant tinnitus. The mean age of these patients was $29.59 \pm 9.3$ years, with a range of 37 years. The mean age of females was $31.63 \pm 7.95$ years and that of males was $25.70 \pm 10.83$ years. 10 patients (34.48\%) were males and 19 (65.52\%) were females (M:F::1:2).

The results of pre- and postoperative hearing assessment are depicted in Table 1.

Table 1: Pre- and postoperative audiological parameters.

\begin{tabular}{|c|c|c|c|}
\hline Parameter & Males & Females & \begin{tabular}{|l|} 
Total \\
\end{tabular} \\
\hline $\begin{array}{l}\text { Pre-op } \\
\text { Air conduction } \\
\text { threshold (ACT) }\end{array}$ & $\begin{array}{l}57.36 \mathrm{~dB} \\
( \pm 11.09)\end{array}$ & $\begin{array}{l}62.42 \mathrm{~dB} \\
( \pm 13.38)\end{array}$ & $\begin{array}{l}60.68 \mathrm{~dB} \\
( \pm 12.67)\end{array}$ \\
\hline $\begin{array}{l}\text { Post-op } \\
\text { Air conduction } \\
\text { threshold (ACT) }\end{array}$ & $\begin{array}{l}37.10 \mathrm{~dB} \\
( \pm 14.38)\end{array}$ & $\begin{array}{l}43.05 \mathrm{~dB} \\
( \pm 14.98)\end{array}$ & $\begin{array}{l}41.00 \mathrm{~dB} \\
( \pm 14.79)\end{array}$ \\
\hline $\begin{array}{l}\text { Air conduction } \\
\text { threshold (ACT) } \\
\text { gain }\end{array}$ & $\begin{array}{l}20.26 \mathrm{~dB} \\
( \pm 05.85)\end{array}$ & $\begin{array}{l}19.37 \mathrm{~dB} \\
( \pm 03.87)\end{array}$ & $\begin{array}{l}19.68 \mathrm{~dB} \\
( \pm 04.56)\end{array}$ \\
\hline $\begin{array}{l}\text { Pre-op Air bone } \\
\text { gap } \\
\text { (ABG) }\end{array}$ & $\begin{array}{l}20.00 \mathrm{~dB} \\
( \pm 06.67)\end{array}$ & $\begin{array}{l}21.58 \mathrm{~dB} \\
( \pm 07.08)\end{array}$ & $\begin{array}{l}21.03 \mathrm{~dB} \\
( \pm 06.86)\end{array}$ \\
\hline $\begin{array}{l}\text { Post-op Air bone } \\
\text { gap (ABG) }\end{array}$ & $\begin{array}{l}09.00 \mathrm{~dB} \\
( \pm 02.11)\end{array}$ & $\begin{array}{l}08.84 \mathrm{~dB} \\
( \pm 03.93)\end{array}$ & $\begin{array}{l}08.90 \mathrm{~dB} \\
( \pm 03.37)\end{array}$ \\
\hline $\begin{array}{l}\text { Air bone gap } \\
\text { closure }\end{array}$ & $\begin{array}{l}11.00 \mathrm{~dB} \\
( \pm 05.68)\end{array}$ & $\begin{array}{l}12.74 \mathrm{~dB} \\
( \pm 06.63)\end{array}$ & $\begin{array}{l}12.14 \mathrm{~dB} \\
( \pm 06.27)\end{array}$ \\
\hline
\end{tabular}


There was improvement in ACT levels and ABG closure in all patients and the difference (pre- and postoperative) was statistically significant (ACT gain:$\mathrm{p}<0.001,95 \% \mathrm{Cl}[17.945$ to 21.414$]$,d.f. 28 , s.e.m 0.847 , t 23.237; ABG closure:- $p<0.001,95 \% \mathrm{Cl}[9.74$ to 14.4 ],d.f. 28 , s.e.m 1.14, t 10.594).

Unilateral tinnitus was present in 16 (55.17\%) patients and bilateral tinnitus was found in 13 (44.83\%) patients. A total of $19(65.51 \%)$ patients had high-frequency hearing loss on audiometric analysis. Patients with a greater magnitude of hearing loss in terms of higher preoperative ACT levels and bigger Air bone gap had more severe tinnitus. Table 2 details the severity of tinnitus before and after stapedotomy. Table 2: Percentage change in tinnitus severity post stapedotomy procedure $(n=29)$

\begin{tabular}{|l|l|l|l|l|l|}
\hline $\begin{array}{l}\text { Tinnitus } \\
\text { severity }\end{array}$ & Cured & Minimal & Mild & Moderate & Severe \\
\hline $\begin{array}{l}\text { Pre- } \\
\text { operative }\end{array}$ & $\begin{array}{l}\text { Not } \\
\text { applicable }\end{array}$ & $\begin{array}{c}03 \\
(10.34 \%)\end{array}$ & $\begin{array}{l}08 \\
(27.58 \%)\end{array}$ & $\begin{array}{l}07 \\
(24.16 \%)\end{array}$ & $\begin{array}{l}11 \\
(37.92 \%)\end{array}$ \\
\hline $\begin{array}{l}\text { Post- } \\
\text { operative }\end{array}$ & 13 & 09 & 04 & 03 & Nil \\
\hline
\end{tabular}

The change in tinnitus severity was similar across both genders. Both males and females experienced a decrease in symptom severity. This is depicted in Figure 1.

Figure 1: Postoperative change in tinnitus severity in both genders.

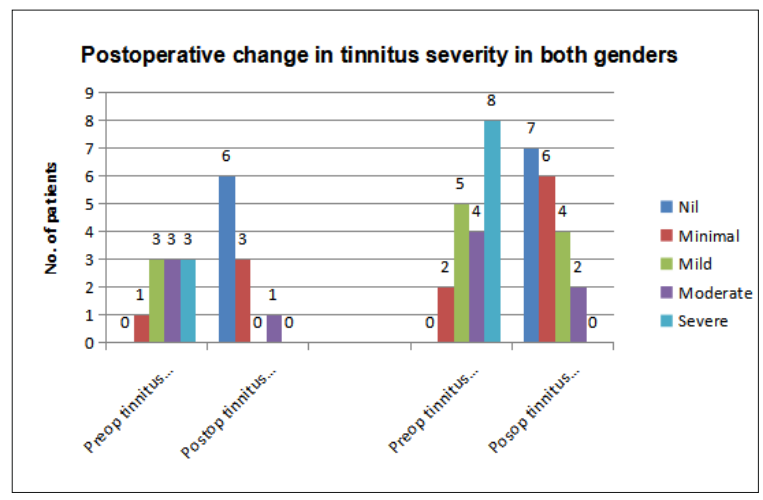

All of our patients reported a reduction in tinnitus sensation and its severity in the post-operative period. We found that patients with a high-frequency hearing loss at presentation had a lesser degree of improvement in tinnitus than those without it. There was a clinical improvement in discomfort, anxiety and lack of sleep associated with tinnitus.

\section{Discussion:}

Tinnitus remains one of the most challenging aspects of otosclerosis management owing to its widely varying prevalence, severity and association with coexisting hearing loss. It can either be the presenting complaint or can develop over years with disease progression.8 Bartnik G. et al. hypothesized that rich vascularization of newly formed otospongiotic focus gives rise to pulsatile tinnitus.11 Ismi et al. also proposed that otosclerotic toxic metabolites can lead to labyrinthine damage. Inner ear fluid vibration compromise due to stapes fixation can also contribute towards the development of tinnitus. 12

The mean age of our patients suffering from otosclerosis induced tinnitus was 29 years. This correlated with the study conducted by Gristwood RE et al. who found that most patients belonged to the 3rd decade of life.13 An approximate $72.5 \%$ of the patients qualifying for stapedotomy reported tinnitus. This is slightly higher than that in other studies by Dziendziel B et al. (64.8\%) and Skarzynski $\mathrm{PH}$ et al. (68.2\%).8,14 About $65 \%$ of our patient population was female. This is supported by other studies that also found a female preponderance in patients with otosclerotic tinnitus. 8 About $44 \%$ of patients had unilateral tinnitus. This was similar to other studies which concluded that both unilateral and bilateral tinnitus is almost equally prevalent.8,9

There was clinically and statistically significant hearing improvement in patients undergoing LASER stapedotomy, as indicated by the gain in air conduction threshold levels and air-bone gap closure values. We also observed that those patients who had a high-frequency loss to begin with, had a poorer outcome. Reduction in severity grade was lesser in these patients when compared to those who did not have a high-frequency hearing loss. This corresponds to the findings of the study by Dan Bagger-Sjöbäck et al. who concluded that high-frequency hearing loss, especially in older patients, was positively associated with worse postoperative hearing outcomes and tinnitus improvement. 15

All the patients of our study group had a reduction in tinnitus severity. There was a complete resolution in about $44 \%$ of the patients. Though a multitude of studies has been conducted to evaluate stapedotomy results, rarely has anyone analyzed its effectiveness in curing tinnitus. Skarzynski P.H. et al. concluded that $70 \%$ of their patients had an improvement in tinnitus post stapedotomy.9 Our significantly higher results may be due to lower 
sample size of our study.

Our study was limited by the fact that it being a retrospective study, tinnitus was not quantified by the use of various tinnitus scoring tools. This limited our scope to numerically correlate tinnitus severity with hearing improvement. The duration of tinnitus was also not included in the study, which could have shed light on its possible role in predicting tinnitus improvement post surgery. Further studies with a larger sample size will be more representative of the benefits of stapedotomy in terms of tinnitus improvement.

This study is the first of its kind in India to the best of our knowledge which assesses the impact of LASER stapedotomy in tinnitus improvement. LASER stapedotomy has come up as the gold standard of surgical management of otosclerosis due to a lesser incidence of perioperative complications and excellent surgical precision associated with the technique. Its efficacy in improving hearing outcomes is well established. Establishing its role in tinnitus improvement will go a long way in helping otologists make an informed choice in surgical technique and offer the best possible option to patients suffering from this insidious but exasperating symptom.

Conclusion: Tinnitus is frequently a ubiquitous debilitating symptom in otosclerotic patients. Its duration and severity vary with the magnitude of hearing loss. High- frequency hearing loss is associated with more severe tinnitus and poorer postoperative improvement. LASER stapedotomy is an effective surgical treatment modality that improves post-operative hearing and simultaneously alleviates tinnitus.

Funding: No funding sources.

Conflict of interest: None declared.

Compliance with ethical standards: All procedures contributing to this study have been conducted complying with the Helsinki Declaration of 1975 institutional guidelines.

\section{Reference:}

1. Ishai R, Halpin CF, Shin JJ, et al. Long-term incidence and degree of sensorineural hearing loss in otosclerosis. OtolNeurotol2016;37:1489-96.

2. Wang PC, Merchant SN, McKenna MJ, et al. Does otosclerosis occur only in the temporal bone? Am J Otol 1999;20:162-5.

3. Batson L, Rizzolo D (2017) Otosclerosis: an update on diagnosis and treatment. JAAPA 30:17-22. https ://doi.org/10.1097/01. JAA.00005 11784.21936.1b.

4. Meyer TA, Lambert PR (2004) Primary and revision stapedectomy in elderly patients. Curr Opin Otolaryngol Head Neck Surg 12:387-392.

5. Skarzynski H, Dziendziel B, Rajchel J, Skarzynski PH (2018) Surgery for juvenile otosclerosis: a literature review. J Hear Sci 8:15-21. https ://doi.org/10.17430/10029 79.

6. Schrauwen I, Khalfallah A, Ealy M, Fransen E, Claes $C$, et al. COL1A1 association and otosclerosis: a metaanalysis. American journal of medical genetics. Part A 2012;158A: 1066-70.

7. Niedermeyer HP, Arnold W. Etiopathogenesis of otosclerosis. ORL. 2002; 64:114-9.

8. Dziendziel B, Skarżyński PH, Rajchel JJ, Gos E, Skarżyński H. Prevalence and severity of tinnitus in Polish otosclerosis patients qualified for stapes surgery. Eur Arch Otorhinolaryngol. 2019 Jun;276(6):15851590.

9. Skarżyński H, Gos E, Dziendziel B, Raj-Koziak D, Włodarczyk EA, Skarżyński PH. Clinically important change in tinnitus sensation after stapedotomy. Health Qual Life Outcomes. 2018Nov 6;16(1):208.

10. Bagger-Sjöbäck, D., Strömbäck, K., Hultcrantz, M.et al. High-frequency hearing, tinnitus and patient satisfaction with stapedotomy: A randomized prospective study. SciRep 5, 13341 (2015).

11. Bartnik G. Szumy uszne i nadwrażliwość słuchowa. In: Skarżyński H, editor. Instytut Fizjologii i Patologii Słuchu. Warszawa; 2010, p.61-3.

12. Ismi O, Erdogan O, Yesilova M, Ozcan C, Ovla D, Gorur K. Does stapes surgery improve tinnitus in patients with otosclerosis? Braz J 
Otorhinolaryngol 2016; 83:568-73.

13. Gristwood RE, Venables WN. 2003. Otosclerosis and chronic tinnitus. The Annals of otology, rhinology, and laryngology 112:398-403.

14. Skarzynski PH, Dziendziel B, Gos E, Wlodarczyk E, Miaskiewicz B, Rajchel JJ, Skarzynski H. Prevalence and Severity of Tinnitus in Otosclerosis: Preliminary Findings from Validated Questionnaires. J Int Adv Otol. 2019 Aug;15(2):277-282.

15. Bagger-Sjöbäck, D., Strömbäck, K., Hultcrantz, M. et al. High-frequency hearing, tinnitus and patient satisfaction with stapedotomy: A randomized prospective study. Sci Rep 5,13341 (2015). https://doi.org/10.1038/srep13341.

\section{*Address for correspondence:}

\section{Swati Suneha}

Senior Resident

Department of Otorhinolaryngology-Head and Neck Surgery,

All India Institute of Medical Sciences, Phulwarisharif Patna-801507, Bihar, India

Email-sunehaswati@gmail.com

Telephone-91-8825304721 